\title{
Effects of Pork Quality Types, Packaging, and Degree of Doneness on Trained Sensory and Instrumental Tenderness, Color, and Consumer Perception
}

\author{
Andrew M. Cassens, Ranjith Ramanathan, Deborah L. VanOverbeke, and Gretchen G. Mafi* \\ Department of Animal and Food Sciences, Oklahoma State University, Stillwater, OK, 74078, USA \\ *Corresponding author. Email: gretchen.mafi@okstate.edu (Gretchen G. Mafi)
}

\begin{abstract}
The objective of this study was to evaluate the palatability and retail display differences of 3 types of pork loins. Enhanced $(n=10)$, nonenhanced $(n=10)$, and high-quality $(n=10)$ pork loins were selected from a commercial food distribution company. Loins were cut into 2.54-cm-thick chops and randomly assigned to retail display, sensory, or Warner-Bratzler shear force analyses. For retail display, chops were randomly assigned to 1 of 3 packaging treatments: polyvinyl chloride overwrap, carbon monoxide-modified atmosphere packaging, and high-oxygen modified atmospheric packaging. Instrumental and visual color measurements were taken during $5 \mathrm{~d}$ of retail display. For trained sensory panel and Warner-Bratzler shear force analyses, chops were evaluated at 3 different degrees of doneness $\left(63^{\circ} \mathrm{C}, 68^{\circ} \mathrm{C}\right.$, and $\left.74^{\circ} \mathrm{C}\right)$. Consumer sensory panelists $(N=50)$ evaluated the overall liking, flavor, juiciness, and tenderness of chops cooked to $68^{\circ} \mathrm{C}$. A treatment $\times$ packaging interaction $(P<0.05)$ occurred for $L^{*}$ and $a^{*}$ values. High-quality chops packaged in polyvinyl chloride overwrap were lighter in color $(P<0.05)$ compared with other treatment and packaging types. However, highquality chops had lower $(P<0.05) a^{*}$ values than other treatment and packaging types during retail display. Trained panelists reported no difference $(P>0.05)$ in tenderness for enhanced chops when cooked at 3 different degrees of doneness. Consumer panelists preferred the enhanced chops for overall liking, tenderness, and juiciness $(P<0.05)$ compared with high-quality and nonenhanced chops. The results suggest that enhanced, nonenhanced, and high-quality pork loins available in the market vary in color and marbling. Both pork loin type and packaging can influence display color and palatability.
\end{abstract}

Key words: pork, enhancement, high-quality, retail, consumers

Meat and Muscle Biology 5(1): 17, 1-12 (2021) doi:10.22175/mmb.11598

Submitted 29 July $2020 \quad$ Accepted 9 February 2021

\section{Introduction}

Pork ranked highest (40.1\%) in the world meat and poultry consumption shares over poultry, beef, and mutton/goat (NPB, 2019). According to the United States Department of Agriculture Foreign Agricultural Services, the US ranked 8th as a country for per-capita pork consumption (NPB, 2019). The end goal for all segments of the pork industry is to provide consumers with a safe and high-quality product. Fresh pork color, pH, water-holding capacity, marbling, and tenderness are important attributes commonly associated with pork quality. Each of these factors, together or separately, has an effect on the cooked product's sensory characteristics, including tenderness, juiciness, and flavor.

Pork color is a key quality factor that can influence the palatability of a product (Richardson et al., 2018). Meat color at the point of purchase is an indicator of freshness and anticipated palatability for pork (Brewer et al., 2002; Richardson et al., 2018). The use of modified atmosphere packaging (MAP) such as carbon monoxide-modified atmosphere packaging (CO-MAP) or high-oxygen-modified atmosphere packaging (HiOx-MAP) has been shown to enhance the color of meat products (Mancini and Hunt, 2005). Though polyvinyl chloride overwrap (PVC) 
packaging is common at retail for pork products, the use of MAP results in a more consistent and stable color.

Savell and Cross (1988) suggested a minimum threshold for intramuscular fat of 3\% for acceptable palatability in red meat, including pork. Marbling has conflicting results when evaluating the impact on pork palatability attributes. DeVol et al. (1988) reported that tenderness was significantly correlated with intramuscular fat $(r=0.34)$ when evaluated by a trained panel. Brewer et al. (2001) noted no statistical difference in consumers' perception of overall juiciness or tenderness for pork based on differences in intramuscular fat. In order to decrease the palatability variation in the pork industry, enhancing pork loins has evolved to satisfy consumers' tastes (Miller, 1998). Most enhancement solutions contain water, salt, phosphate, flavor enhancers, and flavoring agents. The ingredients present in the enhancement solution are key to increasing the water-holding capacity, tenderness, and juiciness of cooked meat products (Lawrence et al., 2004; Baublits et al., 2006).

Consumers demand specific attributes when they purchase food products (Sanders et al., 2007). Therefore, the pork industry needs to understand the particular attributes that consumers evaluate and expect from fresh pork in order to better position the industry in the competitive US meat market. Confusion among consumers on the cooking temperature of pork leads to variability in palatability traits (Prestat et al., 2002). In 2011, the US Department of Agriculture Food Safety and Inspection Service lowered the recommended endpoint temperatures of whole muscle cuts of pork from $71^{\circ} \mathrm{C}$ to $63^{\circ} \mathrm{C}$ in order to maintain food safety but improve sensory traits. Bryhni et al. (2003) evaluated consumers' preference of pork chops cooked at $65^{\circ} \mathrm{C}$ versus $80^{\circ} \mathrm{C}$ and observed that consumers preferred a lower degree of doneness for juiciness and tenderness attributes.

Previous studies have determined the effect that MAP has on the color stability of pork products. However, additional research is needed to understand the effect that packaging has on the retail display of different commercially available types of pork loins. Understanding visual and palatability sensory characteristics of these 3 types of loins by consumers can benefit the pork industry by determining requirements for a positive eating experience. Therefore, the objective of this study was to evaluate the effects of pork loin quality type (high-quality, enhanced, and nonenhanced) on retail display color, tenderness, and consumer perception.

\section{Material and Methods}

\section{Raw materials and processing}

Pork M. longissimus dorsi (Institutional Meat Purchase Specifications \#413) (USDA, 2014) were selected from a commercial food distribution company in Oklahoma. Enhanced $(n=10)$, nonenhanced $(n=$ $10)$, and high-quality $(n=10)$ pork loins were selected with similar pack dates and transported to the Food and Agriculture Products Center at Oklahoma State University. Enhanced pork loins contained a $12 \%$ solution of water and salt. Nonenhanced pork loins were labeled as minimally processed and did not contain any artificial ingredients. The high-quality pork loins were minimally processed and belong to a branded Heritage Duroc Pork Program. To qualify for this branded program, pork loins must have a National Pork Producers Council (1999) (NPPC) color score of 3 or 4 and a marbling score of 3 to 5 .

Pork loins were fabricated 1 to $2 \mathrm{~d}$ postmortem and vacuum packaged $\left(11 \times 22 \mathrm{~cm}^{2}\right.$, 3-mil-highbarrier Cryovac [Sealed Air, Duncan, SC] vacuum bags, standard barrier nylon/polyethylene, $0.6 \mathrm{~cm}^{3}$ $\mathrm{O}_{2} / 645.16 \mathrm{~cm}^{2} / 24 \mathrm{~h}$ at $0^{\circ} \mathrm{C}$ ). The pack date was set as day 0 for aging, and loins were aged in the package for a total of $21 \mathrm{~d}$. Following aging, pork loins were sliced into 2.54-cm-thick chops. Loins were sliced from the posterior end; the first 2 chops were used for proximate analysis. The next chop to posterior end was used for retail display, and the remaining chops were alternated between Warner-Bratzler shear force (WBSF), trained panel, and consumer panel in that order until the M. spinalis dorsi was more than one half the length of the M. longissimus dorsi. Following slicing, chops were vacuum packaged and frozen at approximately $-20^{\circ} \mathrm{C}$ and remained frozen until further analysis.

\section{Proximate composition analysis}

All subcutaneous fat and connective tissue were removed before analysis. Each sample was ground utilizing a tabletop grinder (Big Bite Grinder, $4.5 \mathrm{~mm}$, fine grind; LEM, West Chester, OH). Two-hundredgram samples from enhanced, nonenhanced, and high-quality loins were tightly packed in a $140-\mathrm{mm}$ sample cup and analyzed using an AOAC-approved FOSS Food Scan 78800 near-infrared spectrophotometer (Dedicated Analytical Solutions, Hillerod, Denmark). The proximate composition (protein, water, and fat) was recorded on a percentage basis. 


\section{Muscle $p H$, marbling score, and muscle color score}

Muscle $\mathrm{pH}$ was measured using a portable $\mathrm{pH}$ meter (HI99163 Meat pH Meter; Hanna Instruments, Smithfield, RI). Prior to $\mathrm{pH}$ measurements, the $\mathrm{pH}$ meter was calibrated at $10^{\circ} \mathrm{C}$ using $\mathrm{pH} 4.00$ and 7.00 standard buffers (VWR Analytical, Randor, PA). The $\mathrm{pH}$ of the loin section was measured at 3 different locations by inserting a $\mathrm{pH}$ probe. The mean $\mathrm{pH}$ measurement was calculated and used for statistical analysis.

The first retail display chop sliced from the most posterior end was used for marbling and color scores. Trained panelists $(N=3)$ evaluated visual color and marbling using NPPC standards. Visual color was determined using a 6 -point scale $(1=$ pale, grayishpink; $6=$ dark, purplish-red), and visual marbling was assessed using a 10 -point scale $(1=1 \%$ intramuscular fat; $10=10 \%$ intramuscular fat). All evaluations were made in half score increments.

\section{Retail display}

One chop from each loin was randomly assigned to 1 of 3 packaging treatments: (1) PVC, (2) CO-MAP $\left(0.4 \% \mathrm{CO}, 69.6 \% \mathrm{~N}\right.$, and $\left.30 \% \mathrm{CO}_{2}\right)$, and (3) HiOxMAP $\left(80 \% \mathrm{O}_{2}\right.$ and $\left.20 \% \mathrm{CO}_{2}\right)$. Chops assigned to PVC packaging were placed into a Styrofoam tray with a soaker pad and wrapped with a PVC film $(15,500$ $16,275 \mathrm{~cm}^{3} \mathrm{O}_{2} / \mathrm{m}^{2} / 24 \mathrm{~h}$, at $23^{\circ} \mathrm{C}$, E-Z wrap Crystal Clear Polyvinyl Chloride Wrapping Film, Koch Supplies, Kansas City, MO). Chops assigned to COMAP and HiOx-MAP were placed in Rock-Tenn DuraFresh rigid trays $(22.2 \mathrm{~cm} \times 17.1 \mathrm{~cm} \times 4.5 \mathrm{~cm}$; RockTenn Company, Norcross, GA) and sealed with clear, multilayer barrier film $\left(254 \mathrm{~cm}^{3} \mathrm{O}_{2} / \mathrm{m}^{2} / 24 \mathrm{~h}\right.$, at $4.4^{\circ} \mathrm{C}$, LID 1050 film; Cryovac Sealed Air, Duncan, SC). MAP was accomplished utilizing a Mondini semiautomatic tray-sealing machine (Model CV/VG-5, G.; Mondini, Cologne, Italy) and certified gas blends (Stillwater Steel, Stillwater, OK). Immediately after packaging, packages $(N=27)$ were placed in a coffin-style retail display case under continuous lightemitting diode lighting (Philips LED lamps; $12 \mathrm{~W}$, 48 inches [Philips, China]; color temperature $=3,500$ $\mathrm{K}, 1 \mathrm{x}=900$ ) and maintained at $2^{\circ} \mathrm{C} \pm 1{ }^{\circ} \mathrm{C}$ for $5 \mathrm{~d}$. The packages were rotated daily to minimize the variation due to location within the display case.

A HunterLab MiniScan XE Plus spectrophotometer (2.5-cm aperture, Illuminant $\mathrm{A}$, and $10^{\circ}$ standard observer angle; HunterLab Associates, Reston, VA) was used to measure surface color at 3 locations on each chop on each day of retail display. The objective measure of $L^{*}, a^{*}$, and $b^{*}$ values were utilized to characterize the product's surface color in the package. Care was taken to limit the accumulation of fat and/or moisture smear on the MAP film by carefully flipping the sample over onto the film to conduct color readings, as described in the American Meat Science Association (2012) Meat Color Measurement Guidelines.

A trained color panel was conducted in the retail case under continuous light-emitting diode lighting on day 0,2 , and 4 of the retail display. Muscle color ( $1=$ very bright reddish-pink; $8=\tan$ or brown) and surface discoloration $(1=$ no discoloration $[0 \%] ; 7=$ extensive discoloration [81\%-100\%]) were scored by a 6-member trained panel using American Meat Science Association (2012) Meat Color Measurement Guidelines. Initial muscle color and surface discoloration of bloomed (day 0) chops packaged in PVC was used as a reference for color scoring.

\section{Lipid oxidation}

Following the 5-d retail display, chops were utilized for lipid oxidation measurement. Thiobarbituric acid reactive substance values were determined according to the procedure of Witte et al. (1970). From each chop, a 5-g sample that contained both the interior and surface was blended with $25 \mathrm{~mL}$ trichloroacetic acid solution (20\%) and $20 \mathrm{~mL}$ distilled water. Samples were homogenized using a Sorvall Omni mixer (Newton, CT) for $1 \mathrm{~min}$ and filtered through a Whatman (\#1) filter paper. One milliliter of filtrate was mixed with 1 milliliter thiobarbituric acid solution $(20 \mathrm{mM})$ and incubated in a boiling water bath $\left(95^{\circ} \mathrm{C}\right)$ for $10 \mathrm{~min}$. After incubation, samples were cooled, and absorbance at $532 \mathrm{~nm}$ was measured using a Shimadzu UV-2600 PC spectrophotometer (Shimadzu, Columbia, MD). The blank consisted of $2 \mathrm{~mL}$ trichloroacetic acid/distilled water $(1: 1 \mathrm{v} / \mathrm{v})$ and $2 \mathrm{~mL}$ thiobarbituric acid solution.

\section{Warner-Bratzler shear force}

From each loin, 3 chops were randomly assigned to 3 different endpoint temperatures: $63^{\circ} \mathrm{C}, 68^{\circ} \mathrm{C}$, and $74^{\circ} \mathrm{C}$. Chops were thawed at $4^{\circ} \mathrm{C}$ for approximately $24 \mathrm{~h}$ and cooked utilizing an XLT Impingement Oven (model 3240-TX, BOFI Inc., Wichita, KS). Raw chops were weighed prior to cooking to determine cook loss; this value was recorded as "raw weight." The oven temperature was set to $190^{\circ} \mathrm{C}$, and chops were cooked to their specified internal temperature $\left(63^{\circ} \mathrm{C}, 68^{\circ} \mathrm{C}\right.$, or $74^{\circ} \mathrm{C}$ ). Chops internal temperature was monitored using 
a handheld probe thermometer (AccuTuff 340, Atkins, Gainesville, FL) inserted into the geometric center. Following cooking, chops were weighed and recorded as "cooked weight." The cooked chops were held at $4^{\circ} \mathrm{C}$ for $18 \mathrm{~h}$ to cool. Cook loss was calculated on a percentage basis by subtracting the cooked weight from the raw weight and dividing it by the raw weight. Chilled chops were equilibrated to room temperature before being trimmed of visible fat and connective tissue to expose muscle fiber orientation. Six cores $(1.27 \mathrm{~cm}$ in diameter) were taken by hand from each chop, parallel to the longitudinal orientation of the muscle fibers. An Instron Universal Testing Machine (Model 5943, Instron Corporation, Norwood, MA) was used with a WBSF fixture. Cores were sheared perpendicular to the muscle fibers at a crosshead speed of $200 \mathrm{~mm} / \mathrm{min}$ using the Bluehill 3 software (Instron Corporation). The maximum load (kilograms) was recorded for each core, and the mean maximum load was calculated for each chop.

\section{Trained sensory panel}

Trained sensory panel methods were approved by the Institutional Review Board (AG1932) of Oklahoma State University. Eight panelists from Oklahoma State University were trained to evaluate overall tenderness, juiciness, pork, and salt flavor. Methods for training panelists were similar to those described by Klehm et al. (2018). Pork tenderness was standardized by cooking pork $M$. semimembranosus muscle to an internal temperature of $80^{\circ} \mathrm{C}$ (extremely tough) and pork M. longissimus lumborum to an internal temperature of $63^{\circ} \mathrm{C}$ (extremely tender). Pork juiciness was standardized by cooking pork $M$. semimembranosus muscle to an internal temperature of $80^{\circ} \mathrm{C}$ (extremely dry) and an enhanced ( $20 \%$ of green weight) pork M. longissimus lumborum cooked to an internal temperature of $63^{\circ} \mathrm{C}$ (extremely juicy). Pork flavor was standardized by cooking pork M. longissimus lumborum to an internal temperature of $68^{\circ} \mathrm{C}$ (strongly detectible) and 60\%:40\% lean:fat ground pork to an internal temperature of $71^{\circ} \mathrm{C}$ (not detectible). Salt flavor was standardized by cooking pork $M$. longissimus lumborum with $5 \%$ added salt to an internal temperature of $71^{\circ} \mathrm{C}$ (strongly detectible) and pork M. longissimus lumborum to an internal temperature of $71^{\circ} \mathrm{C}$ (not detectible). Only 6 of the original 8 panelists participated in each trained panel session and were asked to evaluate tenderness $(8=$ extremely tender, $1=$ extremely tough $)$, juiciness $(8=$ extremely juicy, $1=$ extremely dry), pork flavor $(3=$ strongly detectible, $1=$ not detectible $)$, and salt flavor $(3=$ strongly detectible, $1=$ not detectible).

From each loin, 3 chops were randomly assigned to 3 different endpoint temperatures: $63^{\circ} \mathrm{C}, 68^{\circ} \mathrm{C}$, and $74^{\circ} \mathrm{C}$. Panelists evaluated 9 samples per trained panel session $(n=10)$, with 1 chop feeding 3 panelists. Chops were thawed for each session at $4^{\circ} \mathrm{C}$ for approximately $24 \mathrm{~h}$ and cooked utilizing an XLT Impingement Oven (model 3240-TX, BOFI Inc., Wichita, KS). Chops were cooked at $190^{\circ} \mathrm{C}$ to their set endpoint temperature. Chops internal temperature was monitored using a handheld probe thermometer (AccuTuff 340, Atkins, Gainesville, FL) inserted into the geometric center. Chops were cut into $1-\mathrm{cm}^{3}$ cubes, and 2 cubes were placed in a sample cup, assigned a random number, and placed in a warmer to maintain temperature through sensory evaluation. Samples were evaluated under red lighting, and panelists were provided deionized water and unsalted saltine crackers to cleanse their palettes between samples. The 3 trained panelist scores for one chop were averaged to generate mean sensory scores for each palatability trait prior to analysis.

\section{Consumer sensory panel}

A consumer panel was conducted for sensory evaluation, and the methods were approved by the Institutional Review Board (AG1932) of Oklahoma State University. Chops were thawed $(N=39)$ at $4{ }^{\circ} \mathrm{C}$ for approximately $24 \mathrm{~h}$ and cooked utilizing an XLT Impingement Oven (model 3240-TX, BOFI Inc., Wichita, KS). The oven temperature was set to $190^{\circ} \mathrm{C}$, and chops were cooked to $68^{\circ} \mathrm{C}$. Chops internal temperature was monitored using a handheld probe thermometer (AccuTuff 340, Atkins, Gainesville, FL) inserted into the geometric center. Chops were cut into $1-\mathrm{cm}^{3}$ cubes, and 2 cubes were placed in a sample cup, assigned a random number, and placed in a warmer to maintain temperature through sensory evaluation. One pork chop was used to feed 4 consumer panelists, with each panelist evaluating 3 samples. Panelists were provided deionized water and unsalted saltine crackers to cleanse their palettes between samples.

A total of 50 panelists were recruited from Oklahoma State University through e-mail and word of mouth. The consumer sensory panel was conducted in an auditorium located on Oklahoma State University's campus. Panelists were asked to complete a demographics ballot as well as a consent form before beginning the panel. The demographic data from the consumer sensory panel are shown in Table 1 . The auditorium had an open-seating setting, and the 
Table 1. Demographic background of consumer panelists $(N=50)$ for pork chop sensory evaluation

\begin{tabular}{|c|c|}
\hline Parameter & Frequency $(\%)$ \\
\hline \multicolumn{2}{|l|}{ Gender } \\
\hline Male & 48.00 \\
\hline Female & 52.00 \\
\hline \multicolumn{2}{|l|}{ Age, $y$} \\
\hline$<20$ & 12.00 \\
\hline $20-29$ & 38.00 \\
\hline $30-39$ & 12.00 \\
\hline $40-49$ & 8.00 \\
\hline $50-59$ & 14.00 \\
\hline$\geq 60$ & 16.00 \\
\hline \multicolumn{2}{|l|}{ Working Status } \\
\hline Not employed & 5.71 \\
\hline Part-time & 41.43 \\
\hline Full-time & 10.00 \\
\hline Student & 34.29 \\
\hline \multicolumn{2}{|l|}{ Income US\$ } \\
\hline$<20,000$ & 38.00 \\
\hline $20,000-29,999$ & 10.00 \\
\hline $30,000-39,999$ & 12.00 \\
\hline $40,000-49,999$ & 2.00 \\
\hline $50,000-59,999$ & 2.00 \\
\hline$\geq 60,000$ & 36.00 \\
\hline \multicolumn{2}{|l|}{ Urban/Rural } \\
\hline Urban & 48.00 \\
\hline Rural & 52.00 \\
\hline \multicolumn{2}{|l|}{ Pork Chops Consumed } \\
\hline Daily & 0.00 \\
\hline 3 or more times a week & 0.00 \\
\hline Once a week & 32.00 \\
\hline Once a month & 36.00 \\
\hline Once every 2 months & 16.00 \\
\hline 2-3 times a year & 16.00 \\
\hline
\end{tabular}

room had fluorescent lighting, with all 50 panelists completing the survey at the same time. Panelists were asked to evaluate chop attributes based on a 9-point scale. Attributes included overall liking $(1=$ dislike extremely; $9=$ like extremely), flavor liking ( $1=$ dislike extremely; $9=$ like extremely), juiciness liking $(1=$ dislike extremely; $9=$ like extremely $)$, and tenderness liking ( $1=$ dislike extremely; $9=$ like extremely). The 4 consumer panelist scores for one chop were averaged to generate mean sensory scores for each palatability trait prior to analysis.

\section{Statistical analysis}

A split-plot design with repeated measures was utilized for retail display. Pork loin treatment was the whole-plot, and packaging type was the split-plot factor with retail display day as the repeated measure. Fixed effects included pork loin treatment, packaging type, retail display, and their interactions. Loin number was the random effect for the trained color panel, instrumental color, and lipid oxidation. For retail display, the model included pork loin treatment, packaging, retail display day, and their interactions. There was not a significant three-way interaction; therefore, the highest-order two-way interactions are reported. Leastsquares means were calculated, where analysis of variance testing indicated significance, means were separated using the PDIFF procedure and $\alpha<0.05$.

For WBSF, cook loss, and trained sensory panel, a $3 \times 3$ factorial was utilized with pork loin treatment and endpoint temperature. Order and chop number was the random effect for the trained sensory panel. The loin was the random effect for WBSF and cook loss. Models included pork loin treatment and endpoint temperature as main effects and pork loin treatment $\times$ endpoint temperature for a two-way interaction. For the NPPC marbling and muscle color scores, muscle $\mathrm{pH}$, proximate analysis, and consumer sensory panel, one factor randomized design was utilized with pork loin treatment. Order and chop number were the random effects for consumer sensory panel analysis, and loin was the random effect for NPPC marbling and muscle color scores, muscle $\mathrm{pH}$, and proximate analysis. Data were analyzed using the PROC GLM procedure of SAS (version 9.4; SAS Institute Inc., Cary, NC). Least-squares means were calculated; where analysis of variance testing indicated significance, means were separated using the PDIFF procedure and $\alpha<0.05$.

\section{Results and Discussion}

\section{Proximate analysis}

The percentage protein, fat, and moisture are presented in Table 2. Enhanced pork loins had the lowest $(P<0.05)$ protein $(22.19 \%)$ and the highest $(P<0.05)$ moisture $(74.28 \%)$ compared with high-quality and nonenhanced pork loins. The increase in moisture can be attributed to the $12 \%$ added solution in the pork loins. In addition, high-quality pork loins had the highest $(P<0.05)$ fat percentage in comparison to enhanced and nonenhanced loins. High-quality loins had a fat percent of 4.72 , which is representative of an NPPC marbling score of 4 . The mean percentage fat for nonenhanced and enhanced pork loins were greater than expected. A study conducted by Klehm 
Table 2. Least-squares means for NPPC marbling and muscle color scores ${ }^{1}$, proximate compositions, and $\mathrm{pH}$ of high-quality, enhanced, and nonenhanced pork loins

\begin{tabular}{|c|c|c|c|c|c|c|}
\hline \multirow[b]{2}{*}{ Treatment } & \multicolumn{6}{|l|}{ Parameter } \\
\hline & Marbling Score & Muscle Color Score & Fat, $\%$ & Protein, $\%$ & Moisture, $\%$ & $\mathrm{pH}$ \\
\hline High-quality & $3.30^{\mathrm{a}}$ & $3.26^{\mathrm{b}}$ & $4.72^{\mathrm{a}}$ & $23.06^{\mathrm{a}}$ & $71.55^{\mathrm{c}}$ & $5.47^{\mathrm{b}}$ \\
\hline Enhanced & $1.70^{\mathrm{c}}$ & $3.91^{\mathrm{a}}$ & $2.41^{\mathrm{b}}$ & $22.19^{\mathrm{b}}$ & $74.28^{\mathrm{a}}$ & $5.91^{\mathrm{a}}$ \\
\hline Nonenhanced & $2.20^{\mathrm{b}}$ & $3.28^{\mathrm{b}}$ & $2.77^{\mathrm{b}}$ & $23.56^{\mathrm{a}}$ & $73.01^{\mathrm{b}}$ & $5.45^{\mathrm{b}}$ \\
\hline SEM & 0.17 & 0.15 & 0.37 & 0.20 & 0.31 & 0.03 \\
\hline
\end{tabular}

$n=10$ for high-quality, enhanced, and nonenhanced; total sample size $=30$.

${ }^{1}$ Evaluators used National Pork Producers Council (1999) guidelines to assign a marbling and muscle color score: marbling score assigned using a 10-point scale $(1=1 \%$ intramuscular fat; $10=10 \%$ intramuscular fat $)$, muscle color score assigned using a 6 -point scale $(1=$ pale, grayish-pink; $6=$ dark, purplishred).

${ }^{\mathrm{a}-\mathrm{c}}$ Within a column, means lacking a common superscript differ $(P<0.05)$.

$\mathrm{NPPC}=$ National Pork Producers Council; SEM = standard error of the mean .

et al. (2018) evaluated loins selected based upon lean growth or meat quality production focus with leaner loins containing a mean extractable lipid percent of 2.12. It was expected that nonenhanced and enhanced loins for the current study would fall closer to the lean growth production focus value seen in Klehm et al. (2018).

\section{Marbling score, color score, and muscle $\mathrm{pH}$}

Marbling score, color score, and muscle $\mathrm{pH}$ are presented in Table 2. Evaluators used the NPPC guide to assign a marbling and color score for each loin. The high-quality loins had the highest $(P<0.05)$ marbling score (3.30) compared with both enhanced and nonenhanced pork loins (1.70 and 2.20, respectively). Enhanced pork loins had the lowest $(P<0.05)$ marbling score at 1.70. Wright et al. (2005) completed a retail study among 8 US cities and over 200 retail stores and observed that the mean NPPC marbling score was 2.37. Klinkner (2013) conducted a similar retail benchmark study on 117 supermarkets in 67 cities and reported that the mean subjective marbling score in 2013 was 2.30. Based on data from these studies, the only pork loins that fall above that marbling score (2.30) would be the high-quality pork loins with a marbling score of 3.30 .

There was a statistical difference $(P<0.05)$ for subjective NPPC color scores of pork loins. Enhanced pork loins had the highest subjective color score, indicating a darker pink color of lean compared with the high-quality and nonenhanced pork loins. In addition, enhanced loins were shown to have a greater $(P<0.05) \mathrm{pH}$ than high-quality and nonenhanced pork loins, which had a similar $\mathrm{pH}$. Miller (1998) reported that the addition of water, with sodium or phosphate, would promote more binding of moisture within the muscle. This results in less water on the surface, thus allowing less light reflectance and a darker color of lean. The greater $\mathrm{pH}$ may be a cause for the darker pink color of lean seen in enhanced loins. Compared with percentage fat, the lower marbling scores may be due to the trained panelist having a more rigid evaluation of marbling scores.

\section{Retail display}

Instrumental color. There was a significant packaging type $\times$ treatment interaction result for $L^{*}$ and $a^{*}$ values (Table 3 ). High-quality chops packaged in PVC had greater $(P<0.05) L^{*}$ values compared with enhanced and nonenhanced pork chops packaged in PVC. The high-quality chops had a greater amount of marbling, as shown by a greater marbling score and fat percentage (Table 2). The greater amount of intramuscular fat may be the cause of the increased $L^{*}$ values resulting in a brighter/whiter color of lean compared with nonenhanced and enhanced chops because they were leaner chops compared with highquality. There was no difference in $L^{*}$ values $(P>$ $0.05)$ for enhanced chops when packaged in either PVC, CO-MAP, or HiOx-MAP. Contrary to the current study, Krause et al. (2003) reported that enhanced pork chops packaged in CO-MAP had a greater $L^{*}$ value than chops packaged in PVC. Nonenhanced chops packaged in HiOx-MAP had a greater $L^{*}$ value $(P<$ $0.05)$ compared with nonenhanced chops packaged in PVC or CO-MAP. The greater percentage protein and the low percentage fat (Table 2) may be more favorable to a greater oxygen packaging system similar to HiOx-MAP, allowing a more stable and deeper penetration of oxymyoglobin compared with chops with 
Table 3. Least-squares means of $L^{*}$ and $a^{*}$ CIE color space values by packaging type ${ }^{1} \times$ treatment interaction

\begin{tabular}{|c|c|c|c|c|c|c|}
\hline & \multicolumn{3}{|l|}{$L^{*}$} & \multicolumn{3}{|l|}{$a^{*}$} \\
\hline & $\mathrm{PVC}$ & CO-MAP & HiOx-MAP & $\mathrm{PVC}$ & CO-MAP & HiOx-MAP \\
\hline \multicolumn{7}{|l|}{ Treatment } \\
\hline High-quality & $60.26^{\mathrm{a}}$ & $55.51^{\mathrm{bc}}$ & $55.66^{\mathrm{b}}$ & $16.68^{\mathrm{e}}$ & $20.35^{\mathrm{a}}$ & $20.66^{\mathrm{a}}$ \\
\hline Enhanced & $55.21^{\mathrm{bc}}$ & $55.81^{\mathrm{b}}$ & $56.43^{\mathrm{b}}$ & $17.14^{\mathrm{de}}$ & $19.47^{\mathrm{b}}$ & $18.57^{\mathrm{c}}$ \\
\hline Nonenhanced & $54.08^{\mathrm{c}}$ & $55.10^{\mathrm{bc}}$ & $59.37^{\mathrm{a}}$ & $18.40^{\mathrm{c}}$ & $20.41^{\mathrm{a}}$ & $17.61^{\mathrm{d}}$ \\
\hline SEM & 0.76 & & & 0.25 & & \\
\hline
\end{tabular}

$n=3$ for high-quality, enhanced and nonenhanced chops; total sample size $=27$.

${ }^{1}$ Chops from each treatment were packaged in one of 3 packaging types: polyvinyl chloride overwrap (PVC), carbon monoxide modified atmosphere packaging (CO-MAP), and high-oxygen modified atmosphere packaging (HiOx-MAP).

${ }^{\mathrm{a}-\mathrm{e}}$ Means lacking a common superscript within CIE color space value differ $(P<0.0001)$.

$\mathrm{CIE}=$ Commission Internationale de 1'Eclairage ("International Commission on Illumination”); SEM = standard error of the mean.

greater intramuscular fat. Chops packaged in CO-MAP were more consistent among treatment groups as shown by no difference $(P>0.05)$ for $L^{*}$ values between high-quality, enhanced, and nonenhanced pork chops. Krause et al. (2003) reported similar results showing no difference between nonenhanced and enhanced pork chops when packaged in CO-MAP. Packaging in CO-MAP resulted in a more stable carboxymyoglobin formation, which shows no difference in the color development based upon the different pork loin types.

High-quality chops packaged in $\operatorname{PVC}$ had lower $a^{*}$ values $(P<0.05)$ than all packaging $\times$ treatment combinations, except enhanced chops in PVC (Table 3 ). This may be due to the increase in intramuscular fat of high-quality chops. Enhanced and nonenhanced pork chops packaged in CO-MAP had a greater $(P<$ 0.05) $a^{*}$ value in comparison to PVC or HiOx-MAP within treatment groups (Table 3). Krause et al. (2003) had similar results showing that enhanced and nonenhanced pork chops packaged in CO-MAP had a significantly greater $a^{*}$ value than $\mathrm{PVC}$, vacuum package, and MAP using 20\% carbon dioxide and $80 \%$ nitrogen. After day 2 of retail display, COMAP and HiOx-MAP packaged pork chops had a greater $(P<0.05) a^{*}$ value compared with chops packaged in PVC, indicating a more red color (Figure 1). Additionally, on day 3 through 4 of the retail display, there was a significant $(P<0.05)$ difference between all 3 packaging treatments. Pork chops packaged in CO-MAP had a steady increase in $a^{*}$ values from day 3 to day $4(P<0.05)$ compared with both HiOxMAP and PVC packaging treatments. Additionally, HiOx-MAP had a higher $(P<0.05) a^{*}$ value compared with PVC packaging starting on day 2 through 4 of retail display. Krause et al. (2003) had similar results showing an increase in $a^{*}$ values for pork packaged in CO-MAP following day 4 of retail display compared with overwrap packaging.

Trained color panel. There was a significant display day $\times$ packaging type interaction for trained panelists' scores on muscle color and surface discoloration (Table 4). There was an increase $(P<0.05)$ in both muscle color score and surface discoloration score for PVC packaged chops as retail display day increased from day 0 to 4 . For muscle color, there was no difference $(P>0.05)$ between day 2 and 4 for pork chops packaged in CO-MAP. There was a similar difference seen with muscle color scores and $a^{*}$ values (Figure 1) at day 2 and 4 of retail display for pork chops in COMAP. At day 2, pork chops packaged in CO-MAP had lower $(P<0.05)$ muscle color scores indicating a more reddish-pink color compared with PVC packaging. Additionally, at day 4 of retail display, there was a significant difference between all 3 packaging treatments, with CO-MAP having the lowest muscle color score

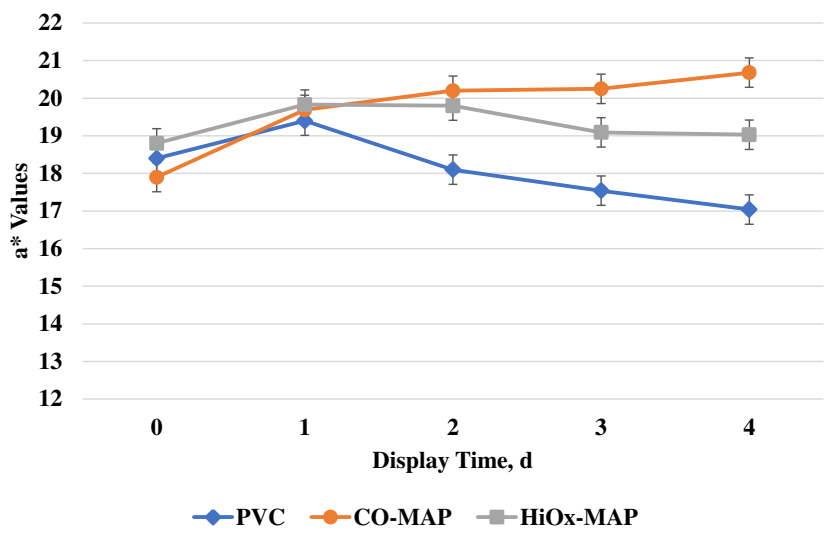

Figure 1. Effects of packaging on pork retail $a^{*}$ values. Pork chops were packaged in one of 3 packaging types: polyvinyl chloride overwrap (PVC), carbon monoxide modified atmosphere packaging (CO-MAP), and high-oxygen modified atmosphere packaging (HiOx-MAP). SEM= 0.39 . SEM $=$ standard error of the mean. 
Table 4. Least-squares means of trained panelists' scores for pork color attributes ${ }^{1}$ by packaging type ${ }^{2} \times$ display $^{2}$ day interaction

\begin{tabular}{|c|c|c|c|c|c|c|}
\hline & \multicolumn{3}{|c|}{ Muscle Color } & \multicolumn{3}{|c|}{ Surface Discoloration } \\
\hline & $\mathrm{PVC}$ & CO-MAP & HiOx-MAP & $\mathrm{PVC}$ & CO-MAP & HiOx-MAP \\
\hline \multicolumn{7}{|c|}{ Display Day } \\
\hline Day 0 & $1.68^{\mathrm{c}}$ & $1.00^{\mathrm{d}}$ & $1.33^{\mathrm{cd}}$ & $1.00^{\mathrm{d}}$ & $1.00^{\mathrm{d}}$ & $1.00^{\mathrm{d}}$ \\
\hline Day 2 & $2.67^{\mathrm{b}}$ & $1.77^{\mathrm{c}}$ & $1.67^{\mathrm{c}}$ & $1.42^{\mathrm{b}}$ & $1.20^{\mathrm{c}}$ & $1.15^{\mathrm{c}}$ \\
\hline Day 4 & $4.66^{\mathrm{a}}$ & $2.05^{\mathrm{c}}$ & $2.46^{\mathrm{b}}$ & $1.85^{\mathrm{a}}$ & $1.34^{\mathrm{b}}$ & $1.33^{\mathrm{b}}$ \\
\hline SEM & \multicolumn{3}{|c|}{0.19} & \multicolumn{3}{|c|}{0.02} \\
\hline
\end{tabular}

$n=3$ for high-quality, enhanced, and nonenhanced chops; total sample size $=27 \times 6$ panelists $=162$.

${ }^{1}$ Panelists used the following scale: muscle color $(1=$ very bright reddish-pink, $2=$ bright reddish-pink, $3=$ dull reddish-pink, $4=$ slightly grayish-pink, $5=$ grayish-pink, $6=$ slightly tannish-gray, $7=$ moderately tannish-gray, $8=\tan$ or brown $)$, surface discoloration $(1=$ no discoloration $[0 \%], 2=$ minimal discoloration $[1 \%-10 \%$ ], $3=$ slight discoloration $[11 \%-20 \%$ ], $4=$ small discoloration $[21 \%-40 \%], 5=$ modest discoloration $[41 \%-60 \%], 6=$ moderate discoloration $[61 \%-80 \%], 7=$ extensive discoloration [81\%-100\%]) using the American Meat Science Association (2012) pork in oxygenated packages and surface discoloration (percentage metmyoglobin formation) meat color measurement guidelines.

${ }^{2}$ Chops from each treatment were packaged in one of 3 packaging types: polyvinyl chloride overwrap (PVC), carbon monoxide modified atmosphere packaging (CO-MAP), and high-oxygen modified atmosphere packaging (HiOx-MAP)

${ }^{\mathrm{a}-\mathrm{d}}$ Means lacking a common superscript within a color attribute differ $(P<0.0001)$.

$\mathrm{SEM}=$ standard error of the mean.

(2.05) indicating a brighter reddish-pink color, followed by HiOx-MAP (2.46) and PVC (4.66). There was no difference $(P>0.05)$ in muscle color for chops packaged in CO-MAP at day 4 of retail compared with PVC packaged pork at day 0. This shows that pork packaged in CO-MAP has similar muscle color at day 4 of retail compared with chops packaged in PVC at day 0 , indicating a longer retail shelf life. Carbon monoxide binds strongly with the meat pigment myoglobin to form stable carboxymyoglobin (Mancini and Hunt, 2005). Similar findings were seen in a study conducted by Sørheim et al. (1999) showing an increase in CO-MAP color stability as retail days increased. The elevated surface discoloration was not evident until day 7 of retail display (Sørheim et al., 1999). For surface discoloration, there was no difference $(P>0.05)$ between CO-MAP and HiOx-MAP throughout the retail display. MAP results in a high concentration of either carbon monoxide or oxygen to bind with myoglobin. Therefore, a greater concentration of carbon monoxide or oxymyoglobin within packages allow gases to penetrate deeper within the muscle, limiting the metmyoglobin layer migrating to the surface during retail display (Taylor and MacDougall, 1973; Ramanathan et al., 2020).

There was a significant treatment $\times$ packaging type interaction for trained panelists' scores on muscle color (Table 5). Pork chops packaged in CO-MAP or HiOxMAP had lower $(P<0.05)$ muscle color scores compared with chops packaged in $\mathrm{PVC}$, indicating a brighter, more reddish-pink color of lean. Greater stability of carboxymyoglobin and oxymyoglobin (within a high-oxygen package) resulted in a more reddishpink color of pork. Furthermore, enhanced and nonenhanced chops had lower $(P<0.05)$ muscle color scores than high-quality chops when packaged in CO-MAP, indicating a brighter, more reddish-pink color of lean.

Lipid oxidation. A treatment $\times$ packaging interaction $(P<0.05)$ was observed for lipid oxidation (Table 6). Nonenhanced chops packaged in PVC had

Table 5. Least-squares means of trained panelists' scores for pork color attributes ${ }^{1}$ by treatment $x$ packaging type ${ }^{2}$ interaction

\begin{tabular}{llll}
\hline \hline & \multicolumn{3}{l}{ Packaging Type } \\
\cline { 2 - 4 } & PVC & CO-MAP & HiOx-MAP \\
\hline Treatment & & & \\
High-quality & $3.01^{\mathrm{a}}$ & $2.06^{\mathrm{b}}$ & $2.12^{\mathrm{b}}$ \\
Enhanced & $2.88^{\mathrm{a}}$ & $1.38^{\mathrm{c}}$ & $1.31^{\mathrm{c}}$ \\
Nonenhanced & $3.13^{\mathrm{a}}$ & $1.38^{\mathrm{c}}$ & $2.03^{\mathrm{b}}$ \\
SEM & 0.19 & & \\
\hline
\end{tabular}

$n=3$ for high-quality, enhanced, and nonenhanced chops; total sample size $=27 \times 6$ panelists $=162$.

${ }^{1}$ Panelists used the following scale: muscle color $(1=$ very bright reddish-pink, $2=$ bright reddish-pink, $3=$ dull reddish-pink, $4=$ slightly grayish-pink, $5=$ grayish-pink, $6=$ slightly tannish-gray, $7=$ moderately tannish-gray, $8=\tan$ or brown) using the American Meat Science Association (2012) pork in oxygenated packages meat color measurement guidelines.

${ }^{2}$ Chops from each treatment were packaged in one of 3 packaging types: polyvinyl chloride overwrap (PVC), carbon monoxide modified atmosphere packaging (CO-MAP), and high-oxygen modified atmosphere packaging (HiOx-MAP).

${ }^{\mathrm{a}-\mathrm{c}}$ Means lacking a common superscript differ $(P<0.0001)$.

SEM, standard error of the mean. 
Table 6. Effects of treatment $\times$ packaging $^{1}$ on lipid oxidation $^{2}$ of pork chops after 5 -d retail display

\begin{tabular}{|c|c|c|c|}
\hline & \multicolumn{3}{|c|}{ Packaging Type } \\
\hline & PVC & CO-MAP & HiOx-MAP \\
\hline \multicolumn{4}{|l|}{ Treatment } \\
\hline High-quality & $0.58^{\mathrm{b}}$ & $0.60^{\mathrm{b}}$ & $0.36^{\mathrm{cd}}$ \\
\hline Enhanced & $0.56^{\mathrm{b}}$ & $0.40^{\mathrm{c}}$ & $0.32^{\mathrm{d}}$ \\
\hline Nonenhanced & $0.76^{\mathrm{a}}$ & $0.31^{\mathrm{d}}$ & $0.32^{\mathrm{d}}$ \\
\hline SEM & \multicolumn{3}{|l|}{0.035} \\
\hline \multicolumn{4}{|c|}{$\begin{aligned} n & =3 \text { for high-quality, enhanced, and nonenhanced chops; total sample } \\
\text { size } & =27 .\end{aligned}$} \\
\hline \multicolumn{4}{|c|}{$\begin{array}{l}{ }^{1} \text { Chops from each treatment were packaged in one of } 3 \text { packaging types: } \\
\text { polyvinyl chloride overwrap (PVC), carbon monoxide modified atmosphere } \\
\text { packaging (CO-MAP), and high-oxygen modified atmosphere packaging } \\
\text { (HiOx-MAP). }\end{array}$} \\
\hline \multicolumn{4}{|c|}{${ }^{2} \mathrm{Lipid}$ oxidation was expressed as $\mathrm{mg} \mathrm{MDA} / \mathrm{kg}$ of meat. } \\
\hline \multicolumn{4}{|c|}{${ }^{\mathrm{a}-\mathrm{d}}$ Means lacking a common superscript differ $(P<0.0001)$. } \\
\hline \multicolumn{4}{|c|}{ MDA, malondialdehyde; } \\
\hline SEM, stan & . & & \\
\hline
\end{tabular}

the highest $(P<0.05)$ lipid oxidation compared with other treatments and packaging types. Furthermore, there was no difference $(P>0.05)$ between treatments for lipid oxidation when packaged in HiOx-MAP. When comparing enhanced and nonenhanced pork chops, chops packaged in CO-MAP had lower $(P<$ $0.05)$ lipid oxidation than PVC packaging. Krause et al. (2003) reported similar findings as shown by less lipid oxidation for enhanced or nonenhanced chops packaged in CO-MAP compared with PVC packaging. A greater oxygen concentration within packages promotes lipid oxidation, thus decreasing shelf life and consumer acceptability (Kim et al., 2010; English et al., 2016). Therefore, it should be expected that HiOxMAP would result in the greatest lipid oxidation. However, based on the current study, HiOx-MAP resulted in among the lowest lipid oxidation following retail display.

\section{Warner-Bratzler shear force}

Table 7 presents the mean WBSF values by treatment and endpoint temperature main effects. Enhanced pork chops had a lower $(P<0.05)$ shear force value $(2.38 \mathrm{~kg})$ compared with nonenhanced pork chops $(2.75 \mathrm{~kg})$. A lower shear force value is indicative of a more tender product. There was no difference $(P>$ 0.05 ) between high-quality and enhanced or high-quality and nonenhanced pork chops. Baublits et al. (2006) reported similar results as shown by a decrease in shear force values for chops enhanced to $12 \%$ compared with nonenhanced chops. The ingredients present in the
Table 7. Least-squares means for WBSF values and cook loss (\%) by treatment and endpoint temperature main effects

\begin{tabular}{lll}
\hline \hline Main Effects & WBSF (kg) & Cook Loss (\%) \\
\hline Treatment & & \\
High-quality & $2.62^{\mathrm{ab}}$ & 20.13 \\
Enhanced & $2.38^{\mathrm{b}}$ & 19.16 \\
Nonenhanced & $2.75^{\mathrm{a}}$ & 19.85 \\
SEM & 0.10 & 0.65 \\
Temperature & \\
$63^{\circ} \mathrm{C}$ & $2.16^{\mathrm{b}}$ & $14.35^{\mathrm{c}}$ \\
$68^{\circ} \mathrm{C}$ & $2.76^{\mathrm{a}}$ & $19.62^{\mathrm{b}}$ \\
$74^{\circ} \mathrm{C}$ & $2.83^{\mathrm{a}}$ & $25.14^{\mathrm{a}}$ \\
SEM & 0.10 & 0.46 \\
\hline$n=10$ for high-quality, enhanced, and nonenhanced $\times 3$ degrees of \\
doneness; total sample size $=90$. \\
a-c Means within a main effect and column lacking a common superscript \\
differ $(P<0.05)$. \\
\multicolumn{2}{l}{ SEM, standard error of the mean; WBSF, Warner-Bratzler shear force. }
\end{tabular}

enhancement solution can decrease shear force by 2 mechanisms. First, the salt can solubilize some of the myofibrillar proteins and also helps to bind with more water, making the product juicier (Miller, 1998). Similar to these findings, Cannata et al. (2010) observed no difference in shear force analysis for chops with an increased amount of intramuscular fat. However, Brewer et al. (2002) showed a decrease in WBSF values for chops that had a greater marbling score (3.21) compared with chops with a lower marbling score (2.47).

In addition, Table 7 presents the endpoint temperature main effect on WBSF values. Pork chops cooked to a lower degree of doneness $\left(63^{\circ} \mathrm{C}\right)$ were more tender $(P<0.05)$ than chops cooked to a greater degree of doneness $\left(68^{\circ} \mathrm{C}\right.$ and $\left.74^{\circ} \mathrm{C}\right)$. Similar findings were observed by Harsh et al. (2018), who noted a lower shear force value for chops cooked at $63^{\circ} \mathrm{C}$ compared with a greater temperature of $71^{\circ} \mathrm{C}$. The National Pork Board recommends cooking pork loin chops to an internal temperature of $145^{\circ} \mathrm{F}\left(63^{\circ} \mathrm{C}\right)(\mathrm{NPB}, 2012)$. Therefore, endpoint cooking temperature is important because it can alter the tenderness of pork chops as shown by the decrease in shear force values.

\section{Cooking loss}

Mean cooking loss percentage values are reported in Table 7. There was no difference $(P>0.05)$ in cook loss between pork quality loin types. This may be attributed to the differences between cooking temperature overpowering the potential pork loin treatment 
differences. As the degree of doneness increased from $63^{\circ} \mathrm{C}$ to $74^{\circ} \mathrm{C}$, there was an increase $(P<0.05)$ in percentage loss during cooking. This is expected because greater cooking temperatures cause greater loss of meat juices and intramuscular fat. Baublits et al. (2006) reported similar findings showing that chops cooked to a greater degree of doneness $\left(82^{\circ} \mathrm{C}\right)$ had a greater cooking loss than chops cooked to a lower degree of doneness $\left(74^{\circ} \mathrm{C}\right)$.

\section{Trained sensory panel}

Table 8 represents the least-squares means of trained panelist scores for overall tenderness by treatment $\times$ endpoint temperature. Enhanced loins showed no difference $(P>0.05)$ with similar tenderness scores at all 3 endpoint temperatures. Baublits et al. (2006) noted similar results that showed no difference in trained panelist tenderness scores for pork chops enhanced with either a $6 \%$ or $12 \%$ solution at various endpoint temperatures. As previously stated, the enhancement process allows for an increase in separation between muscle fibers allowing for a more tender product at various endpoint temperatures (Miller, 1998). When cooking chops to $74^{\circ} \mathrm{C}$, enhanced and high-quality chops were more tender $(P<0.05)$, as shown by a greater tenderness value (5.73) than nonenhanced chops (4.22). Baublits et al. (2006) also showed similar findings, with the pork loins enhanced to either $6 \%$ or $12 \%$ having a greater tenderness value indicating a more tender product compared with nonenhanced chops. Lastly, both high-quality and nonenhanced loins cooked to $63^{\circ} \mathrm{C}$ were rated more tender $(P<0.05)$ by trained panelists than chops of the same treatments

Table 8. Trained panelists' scores $^{1}$ for palatability attribute of pork tenderness palatability by treatment $\times$ endpoint temperature interaction

\begin{tabular}{|c|c|c|c|}
\hline & \multicolumn{3}{|c|}{ Endpoint Temperature } \\
\hline & $63^{\circ} \mathrm{C}$ & $68^{\circ} \mathrm{C}$ & $74^{\circ} \mathrm{C}$ \\
\hline \multicolumn{4}{|l|}{ Treatment } \\
\hline High-quality & $6.38^{\mathrm{a}}$ & $4.73^{b}$ & $5.04^{\mathrm{b}}$ \\
\hline Enhanced & $5.59^{\mathrm{ab}}$ & $5.86^{\mathrm{ab}}$ & $5.73^{\mathrm{ab}}$ \\
\hline Nonenhanced & $6.20^{\mathrm{a}}$ & $5.18^{\mathrm{b}}$ & $4.22^{\mathrm{c}}$ \\
\hline SEM & 0.46 & & \\
\hline \multicolumn{4}{|c|}{$\begin{array}{l}\quad n=10 \text { for high-quality, enhanced, and nonenhanced } \times 3 \text { degrees of } \\
\text { doneness; total sample size }=90 \times 3 \text { panelists per chop }=270 \text {. }\end{array}$} \\
\hline \multicolumn{4}{|c|}{$\begin{array}{l}{ }^{1} \text { Trained panelists used the following scale: overall tenderness was } \\
\text { determined utilizing an } 8 \text {-point scale ( } 1=\text { extremely tough, } 8=\text { extremely } \\
\text { tender). }\end{array}$} \\
\hline \multicolumn{4}{|c|}{${ }^{\mathrm{a}-\mathrm{c}}$ Means lacking a common superscript differ $(P<0.0001)$. } \\
\hline SEM, stand & e mea & & \\
\hline
\end{tabular}

cooked to either $68^{\circ} \mathrm{C}$ or $74^{\circ} \mathrm{C}$. This is in agreement with WBSF force data (Table 7) showing a decrease in tenderness for chops when cooked at a greater endpoint temperature.

Trained panelist scores on juiciness, pork, and salt flavor are shown in Table 9. There was no significant difference $(P<0.05)$ for salt flavor for either treatment and endpoint temperature interactions or main effects. Salt flavor was evaluated to determine whether enhanced loins with the added solution of salt and water had detectible salt flavor compared with other treatments. As the endpoint temperature increased, there was a decrease $(P>0.05)$ in juiciness values indicating a less juicy product. These results align with those reported in Table 7, showing that, as the endpoint temperature increased, the cooking loss increased. Huff-Lonergan et al. (2002) reported a significant correlation for trained panelist scores on tenderness $(r=$ $-0.28)$ and especially juiciness $(r=-0.43)$ when compared with percentage cook loss. A decrease in juiciness may be caused by the loss of moisture and fat during the cooking process. In addition, chops cooked to $68^{\circ} \mathrm{C}$ or $74^{\circ} \mathrm{C}$ had a stronger $(P<0.05)$ pork flavor (2.51 and 2.48, respectfully) compared with chops cooked to $63^{\circ} \mathrm{C}(2.22)$. Heymann et al. (1990) noted similar results that showed a decrease in juiciness and an increase in pork flavor as the internal temperature increased. However, Prestat et al. (2002) showed

Table 9. Least-squares means of trained panelists' scores $^{1}$ for pork palatability attributes by endpoint temperature and treatment main effect

\begin{tabular}{|c|c|c|c|}
\hline & Juiciness Flavor & Pork Flavor & Salt Flavor \\
\hline \multicolumn{4}{|l|}{ Temperature } \\
\hline $63^{\circ} \mathrm{C}$ & $5.58^{\mathrm{a}}$ & $2.22^{\mathrm{b}}$ & 1.38 \\
\hline $68^{\circ} \mathrm{C}$ & $4.77^{b}$ & $2.51^{\mathrm{a}}$ & 1.31 \\
\hline $74^{\circ} \mathrm{C}$ & $3.78^{\mathrm{c}}$ & $2.48^{\mathrm{a}}$ & 1.25 \\
\hline SEM & 0.30 & 0.06 & 0.07 \\
\hline \multicolumn{4}{|l|}{ Treatment } \\
\hline High-quality & 4.92 & 2.34 & 1.30 \\
\hline Enhanced & 4.65 & 2.47 & 1.34 \\
\hline Nonenhanced & 4.59 & 2.41 & 1.30 \\
\hline SEM & 0.23 & 0.08 & 0.07 \\
\hline \multicolumn{4}{|c|}{$\begin{array}{l}n=10 \text { for high-quality, enhanced, and nonenhanced } \times 3 \text { degrees of } \\
\text { doneness; total sample size }=90 \times 3 \text { panelists per chop }=270 \text {. }\end{array}$} \\
\hline \multicolumn{4}{|c|}{$\begin{array}{l}{ }^{1} \text { Trained panelists used the following scale: overall juiciness was } \\
\text { determined utilizing an } 8 \text {-point scale }(1=\text { extremely dry, } 8=\text { extremely } \\
\text { juicy), pork flavor was determined using a } 3 \text {-point scale }(1=\text { not } \\
\text { detectable, } 3=\text { strong), and salt flavor was determined using a } 3 \text {-point } \\
\text { scale }(1=\text { not detectable, } 3=\text { strong). }\end{array}$} \\
\hline \multicolumn{4}{|c|}{${ }^{\mathrm{a}-\mathrm{c}}$ Within a column, means lacking a common superscript differ $(P<$} \\
\hline \multicolumn{4}{|l|}{$0.05)$} \\
\hline
\end{tabular}


no difference for pork flavor or juiciness when comparing different endpoint temperatures, but they did show that cooking nonenhanced chops to a lower degree of doneness resulted in a more juicy product compared with an elevated degree of doneness.

\section{Consumer sensory panel}

Table 10 presents the least-squares means for consumer panelists' scores by treatment. Consumers preferred enhanced pork chops for overall like $(P<$ $0.05)$, tenderness like $(P<0.05)$, and juiciness like $(P<0.05)$ in comparison to high-quality and nonenhanced chops and preferred the flavor of enhanced chops $(P<0.05)$ more than nonenhanced chops. Baublits et al. (2006) had similar findings showing that overall acceptability as well as overall flavor acceptability was statistically greater for enhanced chops than nonenhanced chops as rated by consumers. In addition, high-quality chops were ranked greater for overall like $(P<0.05)$ and juiciness like $(P<0.05)$ compared with nonenhanced chops. Similar to the data seen in WBSF force (Table 7$)$, there was no difference $(P>0.05)$ between the tenderness of high-quality and nonenhanced pork chops (5.35 and 4.87, respectively). There are varying results for intramuscular fat's impact on consumers' perception of juiciness and tenderness. Cannata et al. (2010) showed that, as marbling scores increased, both tenderness and juiciness scores by consumers also increased, indicating a more tender and juicier product. However, Brewer et al. (2001) reported no statistical difference in consumers' perception of overall juiciness or tenderness based on differences

Table 10. Least-squares means of consumer panelists' scores for pork palatability attributes ${ }^{1}$ by treatment main effects

\begin{tabular}{|c|c|c|c|c|}
\hline \multirow[b]{2}{*}{ Treatment } & \multicolumn{4}{|c|}{ Parameter } \\
\hline & $\begin{array}{l}\text { Overall } \\
\text { Like }\end{array}$ & $\begin{array}{l}\text { Flavor } \\
\text { Like }\end{array}$ & $\begin{array}{l}\text { Tenderness } \\
\text { Like }\end{array}$ & $\begin{array}{l}\text { Juiciness } \\
\text { Like }\end{array}$ \\
\hline High-quality & $5.57^{b}$ & $5.64^{\mathrm{ab}}$ & $5.35^{b}$ & $4.86^{b}$ \\
\hline Enhanced & $6.48^{\mathrm{a}}$ & $6.14^{\mathrm{a}}$ & $6.66^{\mathrm{a}}$ & $6.42^{\mathrm{a}}$ \\
\hline Nonenhanced & $4.93^{c}$ & $5.21^{\mathrm{b}}$ & $4.87^{b}$ & $3.93^{\mathrm{c}}$ \\
\hline SEM & 0.27 & 0.28 & 0.31 & 0.29 \\
\hline \multicolumn{5}{|c|}{$\begin{aligned} n & =13 \text { high-quality, enhanced, and nonenhanced chops; total sample } \\
z e & =150 .\end{aligned}$} \\
\hline \multicolumn{5}{|c|}{$\begin{array}{l}{ }^{1} \text { Consumer panelists used the following scale: overall liking }(1=\text { dislike } \\
\text { extremely; } 9=\text { like extremely), flavor liking }(1=\text { dislike extremely; } 9=\text { like } \\
\text { extremely), tenderness liking ( } 1=\text { dislike extremely; } 9=\text { like extremely), } \\
\text { and juiciness liking ( } 1=\text { dislike extremely; } 9=\text { like extremely). }\end{array}$} \\
\hline
\end{tabular}

SEM, standard error of the mean. in intramuscular fat. Though marbling is a common quality factor used to determine a more favorable eating experience for consumers, using additional quality factors with marbling may be more useful to determine the best possible eating experience for consumers of pork products.

\section{Conclusions}

Understanding commercially available pork products is important for the industry to give consumers a positive eating experience. These results show that enhanced, nonenhanced, and high-quality pork loins have different marbling and color parameters at retail that affect cooked product attributes. In the current research, packaging pork chops in CO-MAP resulted in a more stable and desirable reddish-pink color compared with PVC packaging among the different pork loin treatments. Shear force analysis, along with a trained panel, showed the importance of cooking high-quality and nonenhanced chops to a lower degree of doneness. Enhanced chops may be a more reliable option for consumers who prefer a greater degree of doneness to give them a more consistent tender product. Proper education about the degree of doneness, enhancement, and marbling as key quality factors and their effect on palatability is extremely important, which may allow for less variation among different types of pork loins.

\section{Literature Cited}

American Meat Science Association. 2012. AMSA Meat Color Measurement Guidelines: AMSA. Am. Meat Sci. Assoc., Champaign, IL.

Baublits, R. T., J. F. Meullenet, J. T. Sawyer, J. M. Mehaffey, and A. Saha. 2006. Pump rate and cooked temperature effects on pork loin instrumental, sensory descriptive and consumerrated characteristics. Meat Sci. 72:741-750. https://doi.org/ 10.1016/j.meatsci.2005.10.006.

Brewer, M. S., J. Jensen, A. A. Sosnicki, B. Fields, E. Wilson, and F. K. McKeith. 2002. The effect of pig genetics on palatability, color and physical characteristics of fresh pork loin chops. Meat Sci. 61:249-256. https://doi.org/10.1016/S0309-1740 (01)00190-5.

Brewer, M. S., L. G. Zhu, and F. K. McKeith. 2001. Marbling effects on quality characteristics of pork loin chops: consumer purchase intent, visual and sensory characteristics. Meat Sci. 59:153-163. https://doi.org/10.1016/S0309-1740(01) 00065-1.

Bryhni, E. A., D. V. Byrne, M. Rødbotten, S. Møller, C. ClaudiMagnussen, A. Karlsson, H. Agerhem, M. Johansson, and M. Martens. 2003. Consumer and sensory investigations in 
relation to physical/chemical aspects of cooked pork in Scandinavia. Meat Sci. 65:737-748. https://doi.org/10.1016/ S0309-1740(02)00276-0.

Cannata, S., T. E. Engle, S. J. Moeller, H. N. Zerby, A. E. Radunz, M. D. Green, P. D. Bass, and K. E. Belk. 2010. Effect of visual marbling on sensory properties and quality traits of pork loin. Meat Sci. 85:428-434. https://doi.org/10.1016/j.meatsci. 2010.02.011.

DeVol, D. L., F. K. McKeith, P. J. Bechtel, J. Novakofski, R. D. Shanks, and T. R. Carr. 1988. Variation in composition and palatability traits and relationships between muscle characteristics and palatability in a random sample of pork carcasses. J. Anim. Sci. 66:385-395. https://doi.org/10.2527/jas1988. 662385x.

English, A. R., G. G. Mafi, D. L. VanOverbeke, and R. Ramanathan. 2016. Effects of extended aging and modified atmospheric packaging on beef top loin steak color. J. Anim. Sci. 94:1727-1737. https://doi.org/10.2527/jas.20150149 .

Harsh, B., D. Boler, S. Shackelford, and A. Dilger. 2018. Determining the relationship between early postmortem loin quality attributes and aged loin quality attributes using meta-analyses techniques. Meat Muscle Biol. 2:24-24. https://doi.org/10.221751/rmc2018.021.

Heymann, H., H. B. Hedrick, M. A. Karrasch, M. K. Eggeman, and M. R. Ellersieck. 1990. Sensory and chemical characteristics of fresh pork roasts cooked to different endpoint temperatures. J. Food Sci. 55:613-617. https://doi.org/10.1111/j.13652621.1990.tb05189.x.

Huff-Lonergan, E. J., T. J. Baas, M. Malek, J. Dekkers, K. J. Prusa, and M. F. Rothschild. 2002. Correlations among selected pork quality traits. J. Anim. Sci. 80:617. https://doi.org/10.2527/ 2002.803617x.

Kim, Y. H., E. Huff-Lonergan, J. G. Sebranek, and S. M. Lonergan. 2010. High-oxygen modified atmosphere packaging system induces lipid and myoglobin oxidation and protein polymerization. Meat Sci. 85:759-767. https://doi.org/10.1016/j. meatsci.2010.04.001.

Klehm, B. J., D. A. King, A. C. Dilger, S. D. Shackelford, and D. D. Boler. 2018. Effect of packaging type during postmortem aging and degree of doneness on pork chop sensory traits of loins selected to vary in color and marbling. J. Anim Sci. 96:1736-1744. https://doi.org/10.1093/jas/sky084.

Klinkner, B. T. 2013. National retail pork benchmarking study: Characterizing pork quality attributes of multiple cuts in the self-serve meat case. M.S. thesis, North Dakota State University, Fargo, ND. (https://library.ndsu.edu/ir/handle/ 10365/27028).

Krause, T. R., J. G. Sebranek, R. E. Rust, and M. S. Honeyman. 2003. Use of carbon monoxide packaging for improving the shelf life of pork. J. Food Sci. 68:2596-2603. https:// doi.org/10.1111/j.1365-2621.2003.tb07067.x.

Lawrence, T. E., M. E. Dikeman, M. C. Hunt, C. L. Kastner, and D. E. Johnson. 2004. Effects of enhancing beef longissimus with phosphate plus salt, or calcium lactate plus non-phosphate water binders plus rosemary extract. Meat Sci. 67:129-137. https://doi.org/10.1016/j.meatsci.2003.09.015.
Mancini, R. A., and M. C. Hunt. 2005. Current research in meat color. Meat Sci. 71:100-121. https://doi.org/10.1016/j. meatsci.2005.03.003.

Miller, R. 1998. Functionality of non-meat ingredients used in enhanced pork. http://www.meatscience.org/Pubs/factsheets/ functionalitynonmeat.pdf. (Accessed 25 November 2020).

National Pork Producers Council. 1999. Official color and marbling standards. NPPC, Des Moines, IA.

NPB. 2012. Pork temperature. https://www.pork.org/cooking/ pork-temperature/. (Accessed 12 November 2019).

NPB. 2019. World per capita pork consumption. Pork Checkoff. https://www.pork.org/facts/stats/u-s-pork-exports/world-percapita-pork-consumption/. (Accessed 12 November 2019).

Prestat, C., J. Jensen, F. K. McKeith, and M. S. Brewer. 2002. Cooking method and endpoint temperature effects on sensory and color characteristics of pumped pork loin chops. Meat Sci. 60:395-400. https://doi.org/10.1016/S0309-1740(01)001504.

Ramanathan, R., M. C. Hunt, R. A. Mancini, M. N. Nair, M. L. Denzer, S. P. Suman, and G. G. Mafi. 2020. Recent updates in meat color research: Integrating traditional and highthroughput approaches. Meat Muscle Biol. 4:1-24. https:// doi.org/10.22175/mmb.9598.

Richardson, E., B. Fields, A. Dilger, and D. Boler. 2018. The effects of ultimate $\mathrm{pH}$ and color on sensory traits of pork loin chops cooked to a medium-rare degree of doneness. Meat Muscle Biol. 2:90-90. https://doi.org/10.221751/rmc2018.080.

Sanders, D. R., W. Moon, and T. H. Kuethe. 2007. Consumer willingness-to-pay for fresh pork attributes. J. Agribusiness. 25:163-179. https://doi.org/10.22004/ag.econ.62294.

Savell, J., and H. Cross, editors. 1988. The role of fat in the palatability of beef, pork, and lamb. In: Designing foods: Animal product options in the marketplace. National Academy Press, Washington, DC. p. 345-355.

Sørheim, O., H. Nissen, and T. Nesbakken. 1999. The storage life of beef and pork packaged in an atmosphere with low carbon monoxide and high carbon dioxide. Meat Sci. 52:157-164. https://doi.org/10.1016/S0309-1740(98)00163-6.

Taylor, A. A., and D. B. MacDougall. 1973. Fresh beef packed in mixtures of oxygen and carbon dioxide. J. Food Sci. Tech. Mys. 8:453-461. https://doi.org/10.1111/j.1365-2621.1973. tb01732.x.

USDA. 2014. Institutional meat purchase specifications: Fresh pork - Series 400. In: United States Department of Agriculture, editor, Agric. Market. Serv., Washington, DC.

Witte, V. C., G. F. Krause, and M. E. Bailey. 1970. A new extraction method for determining 2-thiobarbituric acid values of pork and beef during storage. J. Food Sci. 35:582-585. https://doi.org/10.1111/j.1365-2621.1970.tb04815.x.

Wright, L. I., J. A. Scanga, K. E. Belk, T. E. Engle, J. D. Tatum, R. C. Person, D. R. McKenna, D. B. Griffin, F. K. McKeith, J. W. Savell, and G. C. Smith. 2005. Benchmarking value in the pork supply chain: Characterization of U.S. pork in the retail marketplace. Meat Sci. 71:451-463. https://doi.org/10.1016/j. meatsci.2005.04.024 